\title{
Swelling Stress and Suction Correlation of Compacted, Heaving Soils
}

\author{
Armand A. Fondjo ${ }^{1}$, Thywill C. Dzogbewu ${ }^{2, *}$ \\ ${ }^{1}$ Department of Civil Engineering, Central University of Technology, Free State, South Africa \\ ${ }^{2}$ Department of Mechanical Engineering, Central University of Technology, Free State, South Africa
}

Received February 20, 2020; Revised March 20, 2020; Accepted May 31, 2020

\begin{abstract}
Copyright $@ 2020$ by authors, all rights reserved. Authors agree that this article remains permanently open access under
\end{abstract} the terms of the Creative Commons Attribution License 4.0 International License

\begin{abstract}
The behaviour of unsaturated soils is mainly influenced by suction. When unsaturated soils display swelling properties, it becomes fundamental to investigate the impact of soil suction on the swelling stress. A survey was done across Free State province in South Africa and samples were obtained from Bloemfontein, Winburg, and Welkom. Geotechnical studies were performed on particle size definition, free swell ratio, free swell index, Atterberg limits, X-ray diffraction, proctor compaction test, soil suction measurement, and constant volume swelling tests to determine the physical and hydro-mechanical properties of the soil samples. According to the findings, at the optimum water content, the swelling stress values are in the range of $177 \mathrm{kPa}$ to $326 \mathrm{kPa}$ which is more than the bearing limit ( $40 \mathrm{kPa}$ ) applied for most lightweight footing. Smectite is identified as the predominant clay mineral in the study areas and has a key influence on the swelling properties. A solid relation is observed between the swelling stress and the soil suctions, with a correlation coefficient value greater than $80 \%$.
\end{abstract}

Keywords Swelling Stress, Suction, Compaction, Heaving Soil, X-ray Diffraction, Optimum Water Content

\section{Introduction and Background}

Heaving soils, predominantly clay exhibits huge volume changes as a result of soil water variation. Foundations built on these soils are exposed to uplift forces induced by swelling stress that can cause cracks, and break up both slabs and building foundations. The behaviour of heaving soils is mainly influenced by suction, which is a free energy state of water inside the soil (Edlefsen and Anderson, 1943). The total suction is formed by the matric suction, represented by $\left(\psi_{\mathrm{m}}\right)$ and the osmotic suction, designated by $\left(\psi_{0}\right)$. Eq.(1) gives the algebraic relation between the constituent's elements of the total suction. Zhang and Lu (2018) investigated the unitary characterisation of the matric suction or negative potential as the free energy variation in a water unit volume state to the free water state. Matric suction is observed as the key parameter determining unsaturated soils behaviour. It is the difference in pressure between the pore air, designated by $\left(\mathrm{u}_{\mathrm{a}}\right)$ and the pore water, designated by $\left(\mathrm{u}_{\mathrm{w}}\right)$ as given in Eq.(2).

$$
\begin{aligned}
& \psi_{t}=\psi_{m}+\psi_{0} \\
& \psi_{m}=u_{a}-u_{w}
\end{aligned}
$$

Swelling stress is the force required to maintain the initial volume when the specimen is subjected to an increment in moisture. The swelling stress can develop significant uplift forces detrimental to the stability of foundations. In this study, the correlation between swelling stress and the soil suctions of compacted heaving soils have been investigated at the optimum water content. The geotechnical index properties and the mineralogy of soil samples are determined. The correlations between the swelling properties and the soil suction, as well as the initial water content and dry unit weight, were investigated.

Studies relating to the relationship between swelling stress and suction are reported in the literature. The hydro-mechanical properties of heaving soil have been analyzed by estimating the swelling stress, soil suction and other related factors by some researchers (Basma et al., 1995; Komine and Ogata, 1994). It is generally reported that the swelling stress does not depend on the initial water content but instead on the void ratio. Besides, the swelling stress increases with the increment of initial dry density and diminishes as the initial water content increases. Nevertheless, this conclusion does not concord with the results of Sridharan et al., (1986) who state that swelling stress decreases upon an increment of initial dry unit weight. If the swelling stress depends on the void 
ratio it cannot be dissociated from the initial water content and the degree of saturation because the voids within unsaturated soils are partially occupied by air and/or water.

Kandemir et al., (1997) attempted to predict the swelling stress from matric suction estimation. Bentonite -Kaolinite clay mixtures are set up to have soils within the range of high plasticity indices. Matric suction is measured utilizing thermocouple psychrometer procedure and zero swelling tests are performed on compacted specimens. A linear correlation is found between logarithmic matric suction and swelling stress. A satisfactory relation between the initial matric suction and the swelling stress does not exist to propose a simple regression equation to predict the swelling stress from matric suction estimation. The experimental results of Kandemir et al., (1997) revealed that the dry unit weight influences the relation between swelling stress and the suction, the swelling stress magnitude increases with the increment of the dry unit weight.

Attom and Barakat (2000) proposed numerical models to predict swelling stress. These numerical models demonstrated that the swelling stress is inversely proportional to the initial water content and directly proportional to the dry unit weight. The results concord with the outcomes of the investigation conducted by Basma et al., (1995); Komine and Ogata (1994); and Rank et al., (2018) on the swelling potential of heaving soil. These results are not in alignment with the study conducted by Sridharan et al., (1986). This can be explained by the fact that the study conducted by Sridharan et al., (1986) is performed on compacted specimens at the optimum water content. Moreover, the swelling stress obtained upon water addition from the specimens with smaller initial water content is higher compared to the swelling stress obtained from the specimens with higher initial water content.

Thakur and Singh (2005) studied the correlation between swelling stress and suction in clay minerals, sodium montmorillonite, and calcium montmorillonite. The suction is measured using a Dew-point potentiometer (WP4). One dimensional expanding stress and free swelling test are conducted to develop the correlation between the swelling stress and the suction. It is observed that swelling stress within calcium montmorillonite is higher than sodium montmorillonite, suction within calcium montmorillonite is lower than sodium montmorillonite and swelling stress increases upon an increment of suction. Therefore, soil mineralogy influences the relation between swelling stress and suction. Erzin and Erol (2007) attempted to describe the swelling stress and suction relationship using compacted samples. A linear relationship is built up between the logarithmic suction and the swelling stress. It is discovered that the initial suction is the most significant condition of suction which characterises the swelling stress. These results are diametrically opposed to the outcomes of the study conducted by Kandemir et al., (1997) who stated that there is no satisfactory relationship between the initial soil suction and the swelling stress to propose a simple regression equation to predict the swelling stress from initial suction estimation.

The relation between swelling stress and suction of compacted heaving soil cannot be dissociated with the impact of dry unit weight and water content on swelling stress. Villar and Lloret (2008) reported that the swelling stress increases exponentially with an increase in dry unit weight. However, the study conducted by Fondjo (2018) on the relationship between the swelling stress and the dry unit weight of compacted specimens at the optimum water content revealed that the swelling stress reduces exponentially upon an increment of dry unit weight. This can be justified by the fact that the swelling stress obtained upon water addition on specimens with smaller initial water content is higher compared to the swelling stress obtained on specimens with higher initial water content.

Basma et al., (1995); Komine and Ogata (1994) studied the impact of the initial water content on swelling stress. Their results reveal that there is no correlation between the swelling stress and the initial water content. These results are not in agreement with the outcomes of the studies conducted by Rank et al., (2018); Cantillo et al., (2017) and Fondjo (2018) on the correlation swelling stress and the initial water content of heaving soils, which revealed that the initial water content influences the swelling stress; as the initial water content increases, the swelling stress increases. Fondjo (2018) reported that at the optimum water content the swelling stress instead decreases with the increment of water content because the maximum air void has been reduced within the soil particles and the dry unit weight can no longer be enhanced by water addition. Therefore, the initial water content cannot be dissociated from the swelling stress.

Agus et al., (2013) investigated the correlation between the swelling stress and the suction of compacted bentonite-sand blends. A series of swelling stress tests were conducted utilizing constant-volume techniques where the initial suction decreased toward zero. The outcomes revealed that the swelling stress increases with the reduction of suction values. The maximum swelling stress is found to be a function of dry unit weight whereas the threshold suction is found to be a function of bentonite content. These results are not in line with the investigations conducted by Kandemir et al., (1997) and Thakur and Singh (2005) on the correlation between swelling stress and the suction, which revealed that the swelling stress increases with the increment of suction. However, the impact of the dry unit weight on the swelling stress concord with the outcomes of the studies conducted by Villar and Lloret (2008), who revealed that the maximum swelling stress increases exponentially with 
increment in initial dry unit weight.

Lightweight structures are the most vulnerable structures experiencing severe defects when built on heaving soil. Nevertheless, swelling stress is generally ignored in engineering practice. Swelling stress can develop significant uplift forces detrimental to the stability of foundations (Figures 5 and 6). Nelson and Miller (1992) suggested the types of foundations to be built on heaving soil: Pier and beam; pile and beam; reinforced rafts, and modified continuous perimeter spread footing. Lucian (2006) recommended that the swelling stress should not exceed the calculated foundation pressure to avoid heave of foundation. Simultaneously, the foundation pressure should not exceed the bearing limit of the soil given by geotechnical studies to reduce foundation displacement.

The literature survey revealed some discrepancies in characterisation of the relationship between swelling stress and suction. Further investigations are required to characterize the relationship between the swelling stress and the soil suction of compacted unsaturated heaving soil, and the impact of swelling stress on foundation failures in the study areas.

\section{Methods}

\subsection{Sample Locations}

Soil samples are collected from various locations across Free State province in South Africa and labeled as follows: Bloemfontein soils (BLS-A; BLS-B; BLS-C); Winburg soils (WBS-A; WBS-B; WBS-C); Welkom soils (WKS-A; WKS-B; WKS-C). The respective GPS coordinates are (BLS-A: 29² $\left.11^{\prime} 49.53^{\prime \prime} \mathrm{S} ; \quad 26^{\circ} 12^{\prime} \quad 52.55^{\prime \prime} \mathrm{E}\right) ; \quad$ (BLS-B: $\left.29^{\circ} 08^{\prime} 04.40^{\prime \prime} \mathrm{S} ; 26^{\circ} 15^{\prime} 58.10^{\prime \prime} \mathrm{E}\right)$; (BLS-C: $29^{\circ} 06^{\prime} 48.20^{\prime \prime} \mathrm{S}$; $26^{\circ} 10^{\prime} 56.70^{\prime \prime E}$ ); (WBS-A: $28^{\circ} 30^{\prime} 43.5^{\prime \prime} \mathrm{S}$; $27^{\circ} 00^{\prime} 12.8^{\prime \prime} \mathrm{E}$ ); (WBS-B: $\left.28^{\circ} 30^{\prime} \quad 59.8^{\prime \prime S} ; \quad 27^{\circ} 00^{\prime} 58.0^{\prime \prime} \mathrm{E}\right) ; \quad$ (WBS-C: $28^{\circ} 31^{\prime} 08.00^{\prime \prime} \mathrm{S} ; 27^{\circ} 00^{\prime} 22.00^{\prime \prime} \mathrm{E}$ ); (WKS-A: $27^{\circ} 57^{\prime} 51.8^{\prime \prime} \mathrm{S}$; $\left.26^{\circ} 45^{\prime} 36.9^{\prime \prime E}\right)$; (WKS-B: $\left.28^{\circ} 00^{\prime} 12.10^{\prime \prime} \mathrm{S} ; 26^{\circ} 43^{\prime} 52.30^{\prime \prime} \mathrm{E}\right)$; (WKS-C: $\left.27^{\circ} 58^{\prime} 15.10^{\prime \prime} \mathrm{S} ; 26^{\circ} 43^{\prime} 05.00^{\prime \prime} \mathrm{E}\right)$.

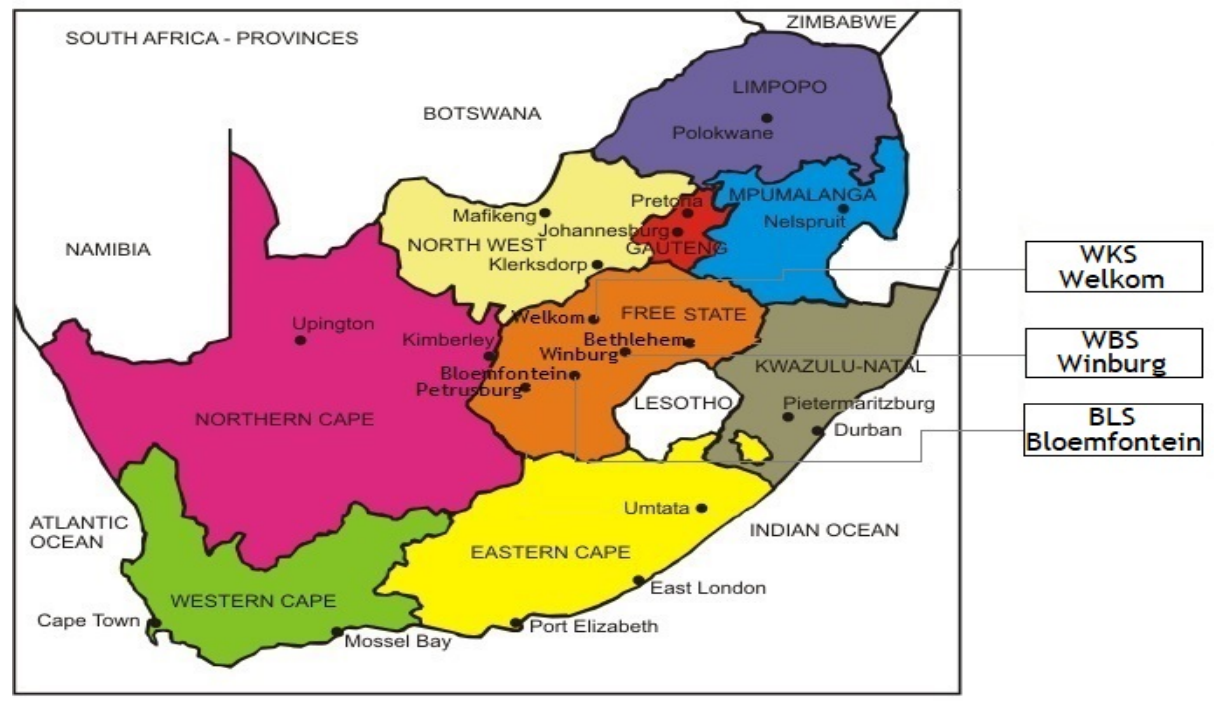

Figure 1. Samples location

\subsection{Laboratory Tests}

Laid down protocols and standards found in the literature to assess the physical and hydro-mechanical properties of the soils are as follows: sieve analysis (ASTM D6913, 2009); hydrometer analysis (ASTM D7928, 2016); Atterberg limits (ASTM D4318, 2005); free swell index (IS: 2720-part 40, 1977); free swell ratio (Sridharan \& Prakash, 2000); X-ray diffraction technique (Brindley and Brown, 1984); Proctor compaction test (SANS 3001-GR30); Soil suction measurement using filter paper technique (ASTM D5298, 2016); zero swelling test (ASTM D4546, 2014).

\subsubsection{Free Swell Index}

The free swell index is the increase in the volume of soil without any external restraints when submerged in water. Two representative oven-dried soil specimens of 10 grams at a temperature of $105^{\circ} \mathrm{C}$ for 16 to 24 hours are sieved through 425-micron sieve. Each soil sample is poured in two glasses graduated cylinders of $100 \mathrm{ml}$ capacity. One cylinder is filled up with kerosene, and another with distilled water up to $100 \mathrm{ml}$ mark. The volume of the specimen read from the cylinder containing distilled water is denoted as $\left(\mathrm{V}_{\mathrm{d}}\right)$, the volume of the specimen read from the cylinder containing kerosene is denoted as $\left(\mathrm{V}_{\mathrm{k}}\right)$. The free swell index is express as:

$$
F S I=100 \times\left(\frac{V_{d-} V_{k}}{V_{k}}\right)
$$


Table 1. Soil expansivity classification using FSI (IS: 2720-Part 40, 1977)

\begin{tabular}{|c|c|c|}
\hline Free swell index, $\%$ & Soil expansivity & Degree of swelling \\
\hline$<50$ & Low & Mixture of swelling and non-swelling \\
\hline $50-100$ & Moderate & swelling \\
\hline $100-200$ & High & High swelling \\
\hline$>200$ & Very high & Very High swelling \\
\hline
\end{tabular}

\subsubsection{Free Swell Ratio}

The free swell ratio is used to evaluate the swelling potential and clay mineralogy. The soil expansivity classification is presented in Table 2. The volume of specimen read from a cylinder containing distilled water is denoted $\left(\mathrm{V}_{\mathrm{d}}\right)$, the volume of the specimen read from a cylinder containing kerosene, is denoted $\left(\mathrm{V}_{\mathrm{k}}\right)$. The free swell ratio is express as:

$$
F S R=\frac{V_{d-} V_{k}}{V_{k}}
$$

Table 2. Soil expansivity classification using FSR (Sridharan \& Prakash, 2000)

\begin{tabular}{|c|c|c|c|}
\hline FSR & Degree of swelling & Soil expansivity & Dominant clay mineral type \\
\hline$=1$ & Non-swelling & Negligible & Kaolinite \\
\hline $1.0-1.5$ & Mixture of swelling and non-swelling & Low & Mixture of kaolinitic and montmorillonitic \\
\hline $1.5-2.0$ & Swelling & Moderate & Montmorillonitic \\
\hline
\end{tabular}

\subsubsection{Swelling Stress Test}

The swelling stress is the maximum external load that is required to prevent swelling soil from any further deformation while wet. Geotechnical engineers usually measure the swelling stress in the laboratory using a conventional consolidometer setup. Basma et al., (1995); Fattom and Barakat (2000) reported that the zero swell test (ZST) is an efficient method to determine the swelling stress of heaving soil. The swelling stress measurement was conducted according to ASTM D4546 on compacted specimens. Before the submergence of the specimen in water, the load bar was reset to zero to measure the vertical displacement of the compacted specimens, tap water was used to soak the specimens, the surcharge is added in small increments to prevent the specimen to swell, this process continues until the specimen ceases to expand. When no further deformation, less than 0.05 is observed for several hours, the experiment is completed, and the total stress applied to prevent the specimen from swelling is called the swelling stress. The total surcharge in $\mathrm{kg}$, denoted by $\left(\sum_{\mathrm{i}=1}^{\mathrm{n}} \mathrm{M}_{\mathrm{i}}\right)$, the gravity in $\mathrm{m} / \mathrm{s}^{2}$, denoted by $(\mathrm{g})$, the beam ratio in $\mathrm{m}$, denoted by $\left(\mathrm{b}_{\mathrm{r}}\right)$, the number of surcharges, denoted by (n), the internal diameter of the consolidating ring in $\mathrm{m}$, denoted by $(\phi)$. The swelling pressure, denoted by $\left(\mathrm{P}_{\mathrm{S}}\right)$ in $\mathrm{kPa}$ is expressed as:

$$
P_{s}=\frac{\frac{\left[\sum_{i=1}^{n} M_{i}\right] \times g \times b_{r}}{\frac{\pi \times \phi^{2}}{4}}}{1000}
$$

\subsubsection{Suction Measurement}

The calibration curve Eq. (7), is established by a calibration process of filter paper using a salt solution. The moisture content within the filter paper, designated as $\left(\mathrm{W}_{\mathrm{f}}\right)$, is estimated using Eq. (8). The calculated moisture content is introduced in Eq. (7) to determine the soil suction. Compacted soil specimens are divided into two cylindrical parts with a width of $75 \mathrm{~mm}$ and a depth of 35 $\mathrm{mm}$ so that the specimen can be placed and removed from the glass jar easily for suction assessment. The suction assessment is performed using the Whatman No 42 type filter paper (Ashless circles $70 \mathrm{~mm}$ diameter, Cat No 1442-070). Three filter papers (two protectives, and one for suction assessment with $70 \mathrm{~mm}$ radius) were placed between these two surfaces using tweezers for matric suction assessment. The two cylindrical specimens' parts are joined using electrical tape and place into a glass jar. A plastic ring is put on top of the soil specimen and the filter papers placed on top of the ring to measure the total suction. The glass jars are labeled, sealed, and placed into a temperature regulatory apparatus at $25 \pm 1^{\circ} \mathrm{C}$ for an equilibrium period of four weeks. The moisture tins were oven-dried at $105^{\circ} \mathrm{C}$ for overnight. Water content within the filter paper is measured using a $0.0001 \mathrm{~g}$ readable balance. The water content of the filter paper, represented by $\left(\mathrm{W}_{\mathrm{f}}\right)$; the mass of water in the filter paper, designated by $\left(\mathrm{M}_{\mathrm{w}}\right)$; and the mass of the filter paper, denoted by $\left(\mathrm{M}_{\mathrm{f}}\right)$. The soil suction, denoted by $(\psi)$ in $\mathrm{kPa}$ is given as:

$$
\begin{gathered}
\log (\psi)=-0.0791 \times W_{f}+5.313 \\
W_{f}=\frac{M_{w}}{M_{f}} \times 100
\end{gathered}
$$




\section{Results and Discussions}

\subsection{Material properties Results}

The material properties of the soil samples used in this study are summarized in Table 3. BLS, WBS, WKS, are fine-grained soil, more than $50 \%$ passing the No $200(0.075 \mathrm{~mm})$. The liquid limit values of BLS, WBS, and WKS are > $50 \%$, these soils exhibit high plasticity, and classified as high plastic clay $(\mathrm{CH})$.

Table 3. Material properties results

\begin{tabular}{|c|c|c|c|c|c|c|c|c|c|}
\hline \multicolumn{2}{|c|}{$\begin{array}{c}\text { Soil } \\
\text { Designation }\end{array}$} & $\begin{array}{c}\text { Liquid } \\
\text { limit (\%) }\end{array}$ & $\begin{array}{l}\text { Plasticity } \\
\text { index (\%) }\end{array}$ & $\begin{array}{l}\text { Clay } \\
(\%)\end{array}$ & $\begin{array}{c}\text { Fine }= \\
\text { Clay + Silt } \\
(\%)\end{array}$ & Sand (\%) & Gravel (\%) & $\begin{array}{c}\text { Specific } \\
\text { gravity }\end{array}$ & USCS* \\
\hline \multirow{3}{*}{ BLS } & BLS-A & 58.98 & 36.82 & 30.40 & 59.51 & 29.39 & 10.09 & 2.64 & $\mathrm{CH}$ \\
\hline & BLS-B & 61.27 & 38.25 & 32.20 & 61.82 & 29.49 & 8.38 & 2.68 & $\mathrm{CH}$ \\
\hline & BLS-C & 64.60 & 40.33 & 35.07 & 65.18 & 30.48 & 4.32 & 2.71 & $\mathrm{CH}$ \\
\hline \multirow{3}{*}{ WBS } & WBS-A & 63.78 & 42.48 & 34.03 & 67.52 & 26.80 & 4.85 & 2.73 & $\mathrm{CH}$ \\
\hline & WBS-B & 66.22 & 44.10 & 36.50 & 70.10 & 27.20 & 2.45 & 2.76 & $\mathrm{CH}$ \\
\hline & WBS-C & 70.64 & 47.04 & 39.73 & 74.78 & 23.98 & 1.21 & 2.78 & $\mathrm{CH}$ \\
\hline \multirow{3}{*}{ WKS } & WKS-A & 69.45 & 49.87 & 40 & 73 & 23.50 & 2.56 & 2.73 & $\mathrm{CH}$ \\
\hline & WKS-B & 74.31 & 53.36 & 48.31 & 78.11 & 18.71 & 1.98 & 2.78 & $\mathrm{CH}$ \\
\hline & WKS-C & 78.94 & 56.68 & 55.25 & 82.98 & 15.92 & 1.10 & 2.83 & $\mathrm{CH}$ \\
\hline
\end{tabular}

*USCS: Unified Soil Classification System

\subsection{Swelling Properties Assessment}

The investigation of the swelling capacity is performed according to the heaving soil classification based on the liquid limit (LL) as proposed by Holtz (1954), based on the free swell ratio (FSR) as proposed by Sridharan and Prakash (2000), and based on the free swell index (FSI) following IS 2720-40. The summary of the investigation of the swelling parameters is presented in Table 4. The results revealed that all the sample exhibits swelling behaviour at various levels. Additionally, some similarities and differences in classification are observed. According to Sridharan and Prakash (2000) and IS 2720-40 classifications, WKS exhibit a high swelling potential whereas BLS and WBS exhibit a moderate swelling potential. Moreover, it can be observed that the Holtz, (1954) classification approach overestimates the swelling potential compared to Sridharan and Prakash (2000) and IS 2720-40 classifications. These discrepancies can be justified by the differences in classification methods. Holtz (1954) classification is based on liquid limit which did not evaluate efficiently the swelling potential because the liquid limit represents the boundary between the plastic state and liquid state. FSR and FSI classifications are better compared to the classification based on the liquid limit.

Table 4. Swelling potential assessment results

\begin{tabular}{|c|c|c|c|c|c|c|c|}
\hline \multicolumn{2}{|c|}{ Soil Designation } & $\begin{array}{c}\text { LL } \\
(\%)\end{array}$ & $\begin{array}{c}\text { Swelling potential } \\
\text { based on LL } \\
\text { (Holtz,1954) }\end{array}$ & FSR & $\begin{array}{c}\text { Swelling potential } \\
\text { (Sridharan \& } \\
\text { Prakash, 2000) }\end{array}$ & $\begin{array}{c}\text { FSI } \\
(\%)\end{array}$ & $\begin{array}{c}\text { Swelling potential } \\
\text { based on FSI } \\
\text { (IS 2720-40) }\end{array}$ \\
\hline \multirow{4}{*}{ BLS } & BLS-A & 58.98 & High & 1.64 & Moderate & 64.31 & Moderate \\
\cline { 2 - 9 } & BLS-B & 61.27 & High & 1.70 & Moderate & 66.66 & Moderate \\
\cline { 2 - 9 } & BLS-C & 64.60 & High & 1.79 & Moderate & 70.19 & Moderate \\
\hline \multirow{4}{*}{ WBS } & WBS-A & 63.78 & High & 1.73 & Moderate & 81.37 & Moderate \\
\cline { 2 - 9 } & WBS-B & 66.22 & High & 1.80 & Moderate & 84.66 & Moderate \\
\cline { 2 - 9 } & WBS-C & 70.64 & Very high & 1.92 & Moderate & 90.30 & Moderate \\
\hline \multirow{4}{*}{ WKS } & WKS-A & 69.45 & High & 2.20 & High swelling & 116.60 & High swelling \\
\cline { 2 - 9 } & WKS-B & 74.31 & Very high & 2.35 & High swelling & 124.60 & High swelling \\
\cline { 2 - 9 } & WKS-C & 78.94 & Very high & 2.50 & High swelling & 132.60 & High swelling \\
\hline
\end{tabular}




\subsection{X-ray Diffraction Results}

Specimens are analyzed for their major mineral contents utilizing the X-ray diffraction technique (Brindley and Brown, 1984). The results revealed that the smectite is found to be the predominant clay mineral in these soils, a very small amount of illite and a trace of illite are found. Quartz, feldspar, and plagioclase are the predominant non-clay mineral, and a very small quantity of calcite and trace of calcite are discovered. The significant amount of smectite content in the soils induces the swelling behavior of these soils.

\subsection{Hydro-mechanical Properties Analysis}

The results of the compaction test, zero swelling test, and soil suction measurement at the optimum water content (OWC) are summarized in Table 6. The OWC and the maximum dry unit weight (MDUW) are obtained from the compaction curves of soils BLS, WBS, and WKS as shown in Figures 2 to 4. It can be noticed that WKS soil exhibits the smaller values of MDUW and the higher values of OWC. BLS soil displays the higher values of MDUW and the smaller values of OWC. WBS soil exhibits the median values of MDUW as well as OWC. These results can be explained by the fact that as the fine soil (Clay + Silt) content increases, the MDUW decreases, and the OWC increases upon the same compaction energy. These results can be also explained by the fact that as the clayey mineral (smectite + illite) content increases, the MDUW decreases, whereas the OWC increases upon the same compaction energy. Furthermore, the swelling stress values and the soil suction values increases as the fine soil fraction increases within the soil, WKS swelling stress values, and suction values are higher. BLS swelling stress values and suction values are smaller. WBS swelling stress values and suction values are median. These results can be explained by the amount of fine soil content in these soils. As mentioned in Table 3, WKS fine soil content is within the range of $73 \%$ to $83 \%$; WBS fine soil content is within the range of $68 \%$ to $75 \%$, and BLS fine soil content is within the range of $60 \%$ to $65 \%$. As presented in Table 5, WKS smectite content is within the range of $67 \%$ to $76 \%$, WBS smectite content is within the range of $58 \%$ to $63 \%$, and BLS smectite content is within the range of $57 \%$ to $61 \%$. Besides, as the amount of fine soil increases, the swelling stress, soil suction increase whereas the MDUW decreases. Lastly, the large differences of compaction curves for each soil can be explained by the differences of fine content, differences of clayey minerals content, and the swelling behaviour.

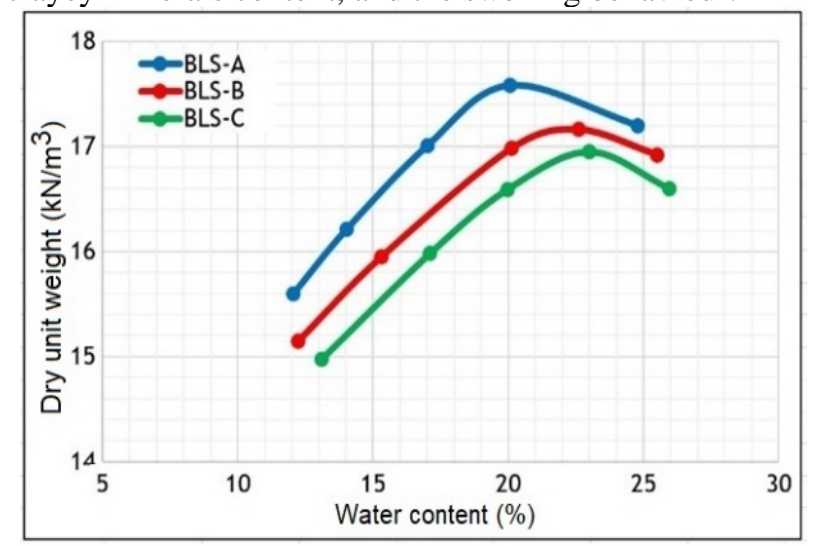

Figure 2. Compaction curves (BLS)

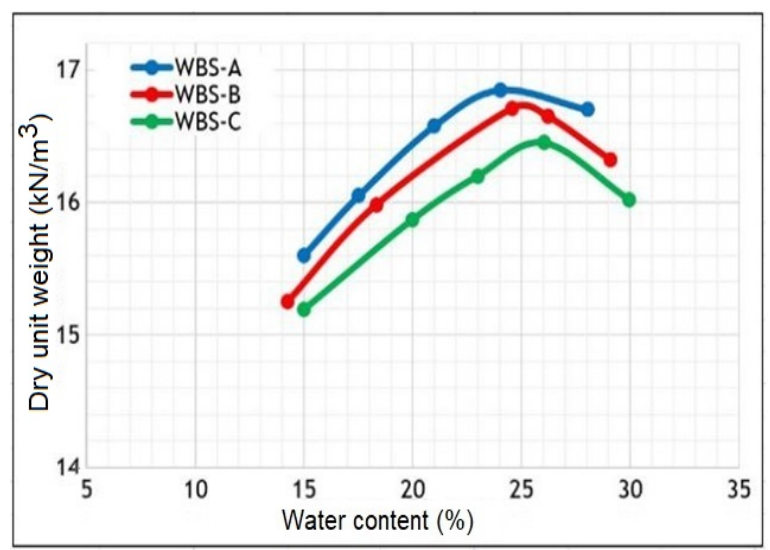

Figure 3. Compaction curves (WBS)

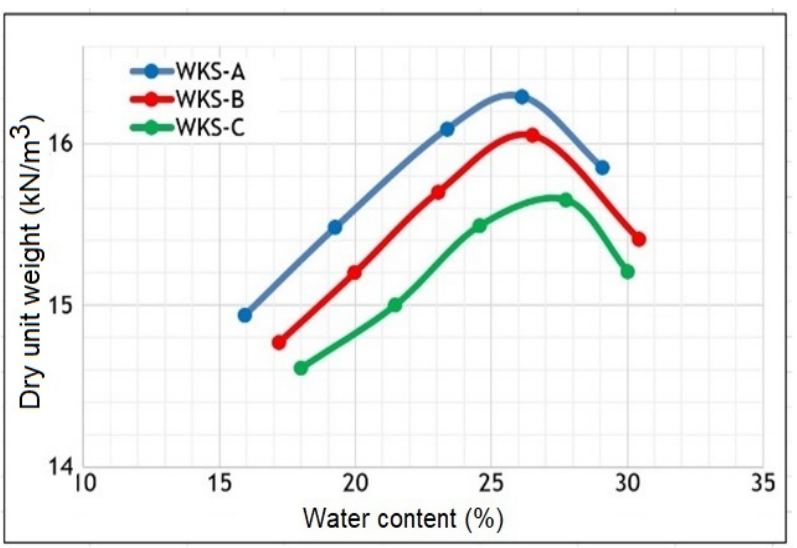

Figure 4. Compaction curves (WKS) 
Table 5. X-ray diffraction results

\begin{tabular}{|c|c|c|c|c|c|c|c|}
\hline \multicolumn{2}{|c|}{ Soil Designation } & Smectite (\%) & Quartz (\%) & K-feldspar (\%) & Plagioclase (\%) & Illite (\%) & Calcite (\%) \\
\hline \multirow{4}{*}{ BLS } & 56.83 & 56.83 & 12.47 & 23.51 & 3.29 & 1.89 & 2.01 \\
\cline { 2 - 9 } & 58 & 58 & 14 & 24.88 & 3.12 & trace & trace \\
\cline { 2 - 9 } & 61.15 & 61.15 & 11.93 & 19.01 & 2.63 & 3.3 & 1.98 \\
\hline \multirow{4}{*}{ WBS } & 58.22 & 58.22 & 25.08 & 10.42 & 2.45 & 2.02 & 1.81 \\
\cline { 2 - 9 } & 59.41 & 59.41 & 27.70 & 9.99 & 2.9 & trace & trace \\
\cline { 2 - 9 } & 63.37 & 63.37 & 20.34 & 10.71 & 1.8 & 2.43 & 1.35 \\
\hline \multirow{4}{*}{ WKS } & 67.05 & 67.05 & 19.98 & 10.66 & 2.31 & trace & trace \\
\cline { 2 - 9 } & 71.74 & 71.74 & 13.40 & 9.91 & 1.85 & 1.89 & 1.22 \\
\cline { 2 - 9 } & 76.21 & 76.21 & 11.69 & 8.57 & 1.25 & 1.14 & 1.18 \\
\hline
\end{tabular}

Table 6. Hydro-mechanical properties

\begin{tabular}{|c|c|c|c|c|c|c|}
\hline $\begin{array}{c}\text { Soil } \\
\text { designation }\end{array}$ & Samples & $\begin{array}{c}\text { Optimum water } \\
\text { content, } \%\end{array}$ & $\begin{array}{c}\text { Maximum dry unit } \\
\text { weight, } \mathrm{kN} / \mathrm{m}^{3}\end{array}$ & $\begin{array}{c}\text { Swelling stress, } \\
\mathrm{kPa}\end{array}$ & $\begin{array}{c}\text { Matric suction, } \\
\mathrm{kPa}\end{array}$ & $\begin{array}{c}\text { Total suction, } \\
\mathrm{kPa}\end{array}$ \\
\hline \multirow{4}{*}{ BLS } & BLS-A & 20.07 & 17.58 & 176.88 & 671.89 & 1036.11 \\
\cline { 2 - 7 } & BLS-B & 22.61 & 17.16 & 187.36 & 697.98 & 1076.32 \\
\cline { 2 - 8 } & BLS-C & 23.00 & 16.95 & 204.06 & 735.90 & 1134.82 \\
\hline \multirow{4}{*}{ WBS } & WBS-A & 24.03 & 16.85 & 232.91 & 1199.35 & 1699.05 \\
\cline { 2 - 8 } & WBS-B & 24.58 & 16.71 & 312.26 & 2853.32 & 3717.73 \\
\cline { 2 - 8 } & WBS-C & 26.05 & 16.45 & 271,92 & 1328.33 & 1881.75 \\
\hline \multirow{3}{*}{ WKS } & WKS-A & 26.14 & 16.29 & 262.30 & 1778.65 & 2475.62 \\
\cline { 2 - 8 } & WKS-B & 26.52 & 16.05 & 361.79 & 1903.16 & 2648.91 \\
\cline { 2 - 8 } & WKS-C & 27.75 & 15.65 & 362.30 & 2021.814 & 2814.07 \\
\hline
\end{tabular}

\subsection{Influence of the Swelling Stress on Lightweight Footing Foundations}

Heaving soils across the study areas exert upward swelling stress above $177 \mathrm{kPa}$, which is greater than the bearing limits $(\sim 40 \mathrm{kPa})$ exerted by most lightweight footings in the study areas. This can justify the defects (cracks, buckling, differential settlement, etc) observed on lightweight constructions as shown in Figures $5 \& 6$ in the study areas. Multistorey buildings in the study areas have no structural damage. These heavier buildings are capable to overcome uplift forces induced by swelling stress. Foundation pressure must exceed the swelling stress to prevent uplift forces. Moreover, the foundation pressure must not exceed the bearing limit of the soil given by geotechnical studies.

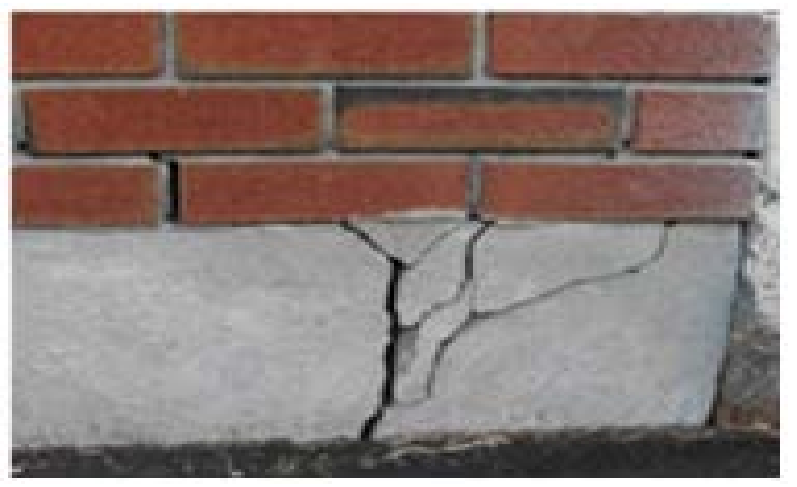

Figure 5. Buckled foundation defect from heaving soils at Kroonstad

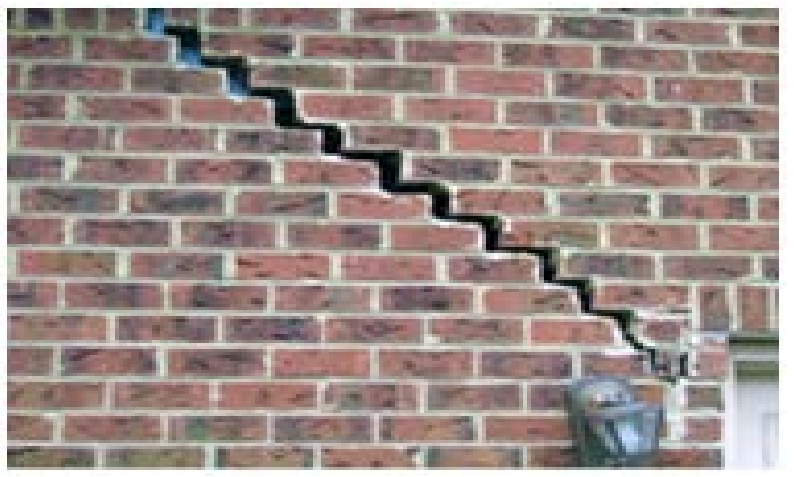

Figure 6. Crack at the corner of the wall opening due to foundation differential settlement caused by heaving soils at Winburg

\subsection{Study of the Correlation between Swelling Stress and the Soil Suction}

The influence of the variation of the total suction values denoted by $\left(\Delta \psi_{\mathrm{t}}\right)$ and the matric suction values designated by $\left(\Delta \psi_{\mathrm{m}}\right)$ on the swelling stress values denoted by $\left(\Delta \mathrm{P}_{\mathrm{S}}\right)$ can be described as follows: The variation in total suction evaluated as $\Delta \psi_{\mathrm{t}}=1778 \mathrm{kPa}$ as well as a change in matric suction estimated as $\Delta \psi_{\mathrm{m}}=1350 \mathrm{kPa}$ induces a change in swelling stress at the OWC content estimated at $\Delta \mathrm{P}_{\mathrm{S}}=185 \mathrm{kPa}$.

Hence, the variation of the soil suction in compacted heaving soil impacts the swelling stress values. Besides, the influence of the total suction on the swelling stress is greater than the effect of matric suction on the swelling 
stress. This can be explained by the fact that total suction is greater than the matric suction.

Additionally, to investigate the correlations between the swelling stress and the soil suctions, the experimental data obtained from geotechnical studies (Table 6) are plotted (Figures 7), and a three variables model including swelling stress, total suction, and the matric suction is shown in Figure 8 (data from Table 6).

The correlations between the swelling stress and the total suction are shown in Figure 7(a). The results revealed an increase of swelling stress as the total suction increases and portrayed an exponential relationship with very small disparities for the soil samples BLS, WBS, and WKS. The trend line equation is given as: $P_{S}=$ $152 \mathrm{e}^{0.003 \psi_{\mathrm{t}}}$, with a correlation coefficient $\mathrm{R}^{2}=85 \%$. There is a strong correlation between the swelling stress and the total suction since the coefficient of correlation exceeds $80 \%$ for soils BLS, WBS, and WKS. Also, the correlation between swelling stress and matric suction is shown in Figure 7(b). The swelling stress increases as the matric suction increases and exhibits an exponential relationship with very small discrepancies for the soil samples BLS, WBS, and WKS. The trend line equation is given as: $P_{S}=163 \mathrm{e}^{0.003} \psi_{\mathrm{m}}$, with a correlation coefficient $\mathrm{R}^{2}=81 \%$. There is a strong correlation between the swelling stress and the matric suction since the coefficient of correlation exceeds $80 \%$ for all the soils. Three-dimension modeling of the correlation between the swelling stress, the total suction, and the matric suction is illustrated in Figure 8 (data from table 6). Colours patterns are used to represent the various range of swelling stress and soil suction values. The light blue and dark blue colours represent the smaller values of swelling stress, the orange patterns represent the median values of the swelling stress, the red and dark red colours represent the higher values of the swelling stress evaluated as $362 \mathrm{kPa}$. The shape of the surface plot portrayed an increment of the swelling stress upon the increasing of total suction as well as the matric suction.

It came to light that; the swelling stress variation cannot be dissociated from the change in soil suction in heaving soils. These results are in line with the studies conducted by Rao et al., (2004) on the correlation between swelling stress and soil suction, it is found that the swelling stress increases as the soil suction increases. Additionally, the results are also in line with the investigation carried out by Kandemir et al., (1977) and Thakur and Singh (2005). Moreover, the investigation by Wójcik and Gawriuczenkow (2017) on the swelling stress and swell index from the suction test on precompacted Neogene clays in Warsaw Poland shows an exponential correlation between the soil swelling stress and the suction, as the suction increases, the swelling stress increases. However, these results contradict the outcomes of the studies conducted by Agus et al., (2013) who reported that the swelling stress decreases upon the increase of the soil suction. By and large, the swelling stress of heaving soil is significantly influenced by the soil suction.

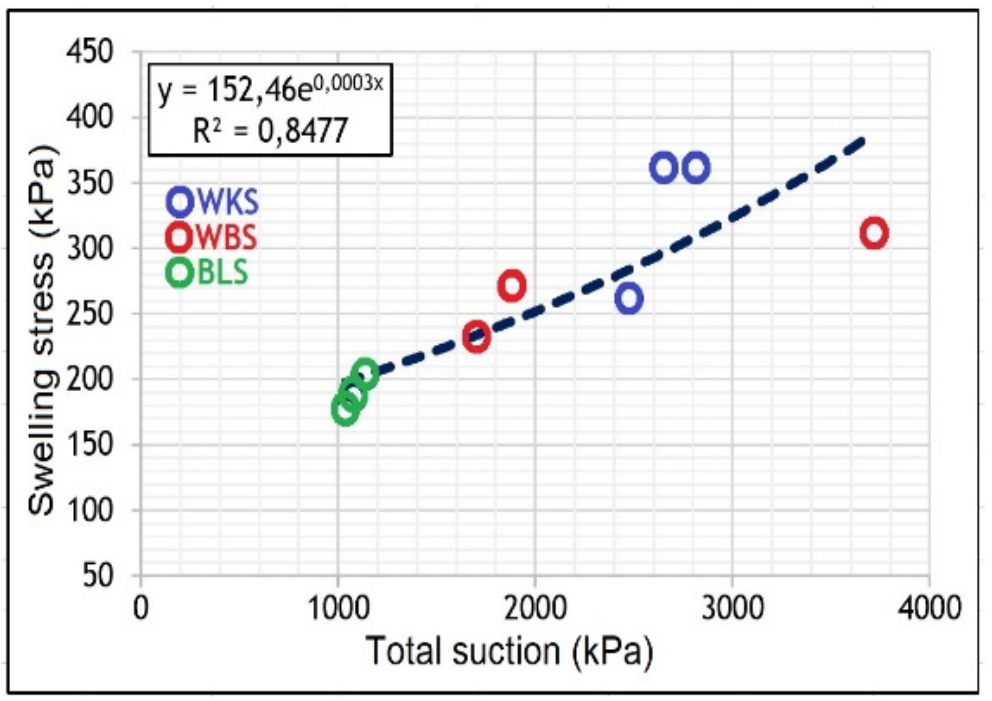

(a) Swelling stress vs total suction 


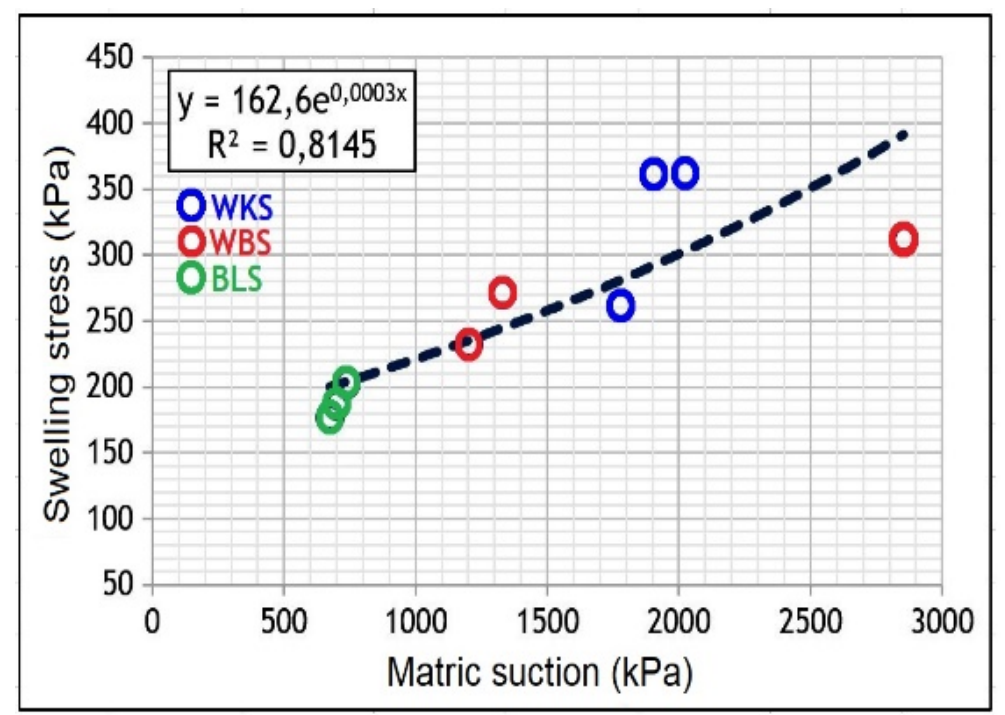

(b) Swelling stress vs matric suction

Figure 7. Swelling stress vs soil suction (total suction, matric suction) @ OWC
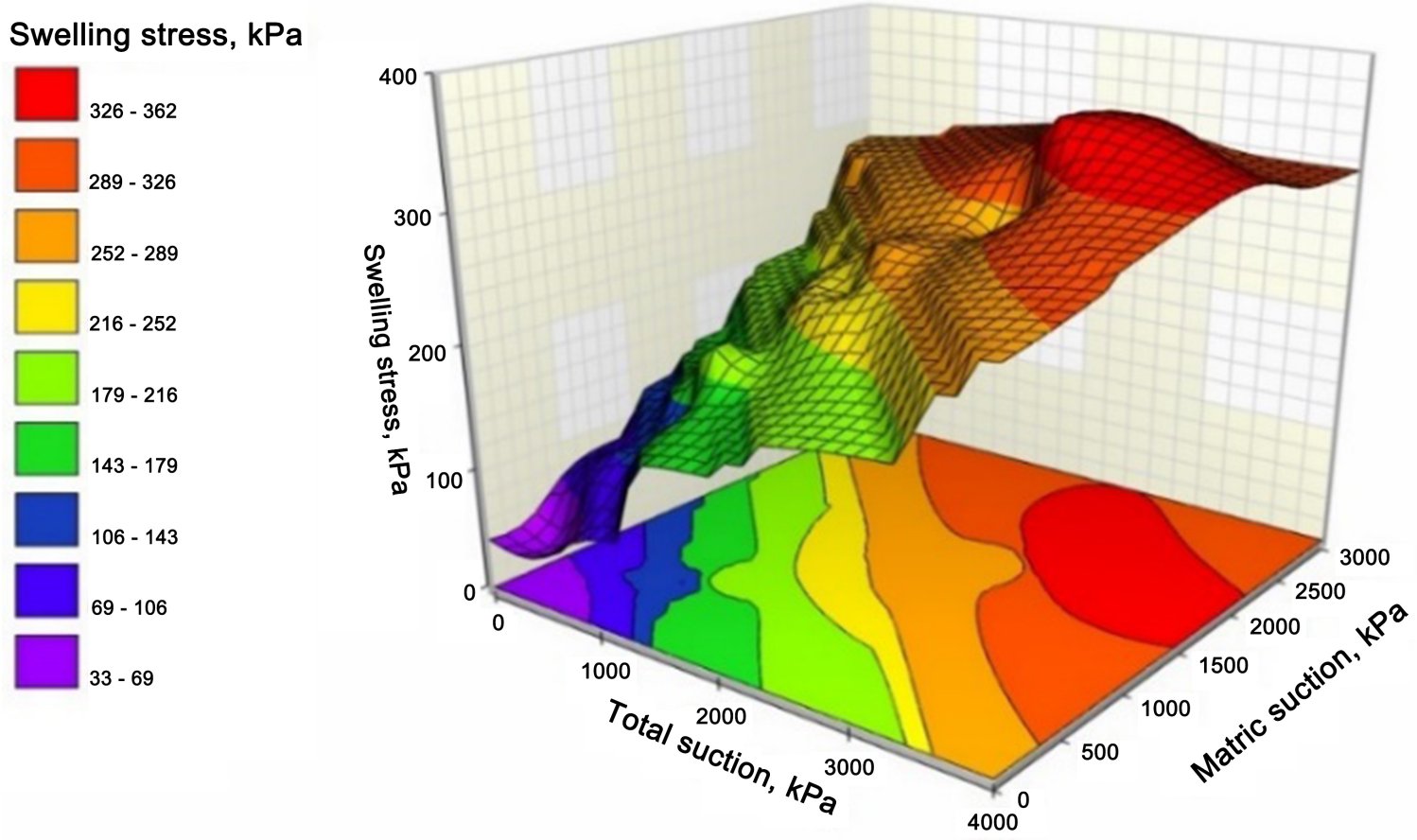

Figure 8. Surface plot of swelling stress vs total suction. Matric suction @ OWC

\subsection{Study of the Correlation between Swelling Stress,} Initial Water Content, and Initial Dry Density

The influence of the variation in initial water content values denoted by $\left(\Delta \mathrm{W}_{\mathrm{i}}\right)$ and the variation of initial dry unit weight values designated by $\left(\Delta \gamma_{\mathrm{i}}\right)$ on the swelling stress values denoted by $\left(\Delta \mathrm{P}_{\mathrm{S}}\right)$ can be described as follows: The variation in initial water content evaluated as $\Delta \mathrm{W}_{\mathrm{i}}=8 \%$ and the variation in initial dry unit weight estimated as $\Delta \gamma_{\mathrm{i}}=2 \mathrm{kN} / \mathrm{m}^{3}$ induces a change in swelling stress estimated as $\Delta \mathrm{P}_{\mathrm{S}}=185 \mathrm{kPa}$ at the OWC. From the results, it could be concluded that, the variation of the initial water content and the dry unit weight within a compacted heaving soil influence the swelling stress values. Moreover, to investigate the correlations between the swelling stress, the initial water content, and initial dry unit weight, experimental data obtained from the geotechnical studies (Table 6) are plotted in graphs shown in Figure 9(a) and Figure 9(b). Also, three-dimension modeling of the relationship between the swelling stress, initial water content, and initial dry unit weight is represented in Figure 10 (data from Table 6).

The correlation between swelling stress and the initial water content at the optimum water content is shown in 
Figure 9(a). A tendency of increment of the swelling stress as the initial water content increase was noticed and portrayed an exponential relationship with very small discrepancies for the soil samples BLS, WBS, and WKS. The trend line equation is given as: $P_{S}=21 e^{0.10 W_{i}}$, with a correlation coefficient $\mathrm{R}^{2}=80 \%$. There is a strong correlation between the swelling stress and the initial water content since the correlation coefficient exceeds $80 \%$ for all soils. These results are in accordance with the outcome of the investigation conducted by Rank et al., (2018) on the behaviour of clay collected from various locations across India which revealed that the swelling stress increases as the initial water content increases and the results of the investigations conducted by Sridharan et al.,(1986). Also, the results did not concord with the study conducted by Cantillo et al., (2017) on empirical correlations for the swelling stress of heaving clays from the city of Barranquilla, Colombia. This can be explained by the fact that at the optimum water content, the maximum air void has been reduced within the soil particles, and the dry unit weight can no longer be enhanced upon water addition. Therefore, the swelling stress increases upon increment in initial water content.

The correlation between the swelling stress and the initial dry unit weight is shown in Figure 9(b). The correlation portrays a decrease of swelling stress as the initial dry unit weight increases and displays an exponential relationship with very small disparities for the soil samples BLS, WBS, and WKS. The trend line equation is given as: $P_{S}=2512 \mathrm{e}^{-0.41 \gamma_{i}}$, with a correlation coefficient $\mathrm{R}^{2}=83 \%$. A strong correlation between the swelling stress and the initial dry unit weight is noticed, the coefficient of correlation is greater than $80 \%$ for all soils. These results concord with the outcome of the investigation conducted by Rank et al., (2018) on the behaviour of clay collected from various locations across India which revealed that the swelling stress decrease as the initial dry unit weight increases. Moreover, Sridharan et al., (1986) reported that the swelling stress decreases as the initial dry unit weight increases. On the other hand, Basma et al., (1995); Komine and Ogata; (1994); Attom and Barakat (2000) reported that the swelling stress increases upon an increment of initial water content. These discrepancies can be justified by the fact that the swelling stress obtained upon water addition from the specimens with smaller initial water content is higher compared to the swelling stress obtained from the specimen with higher initial water content.

Three-dimension modeling of the correlations between the swelling stress, initial water content, initial dry unit weight is shown in Figure 10. Colours patterns are used to represent various range of swelling stress values, initial water content, and initial dry unit weight values. The light blue and dark blue colours represent the smaller values of swelling stress, the orange patterns represent the median values of the swelling stress, the red and dark red colours the higher values of the swelling stress evaluated as 362 $\mathrm{kPa}$. The shape of the surface plot at the optimal water content displays an augmentation of the swelling stress upon the increment of the initial water content, and a reduction of the swelling stress with the increment of the initial dry unit weight.

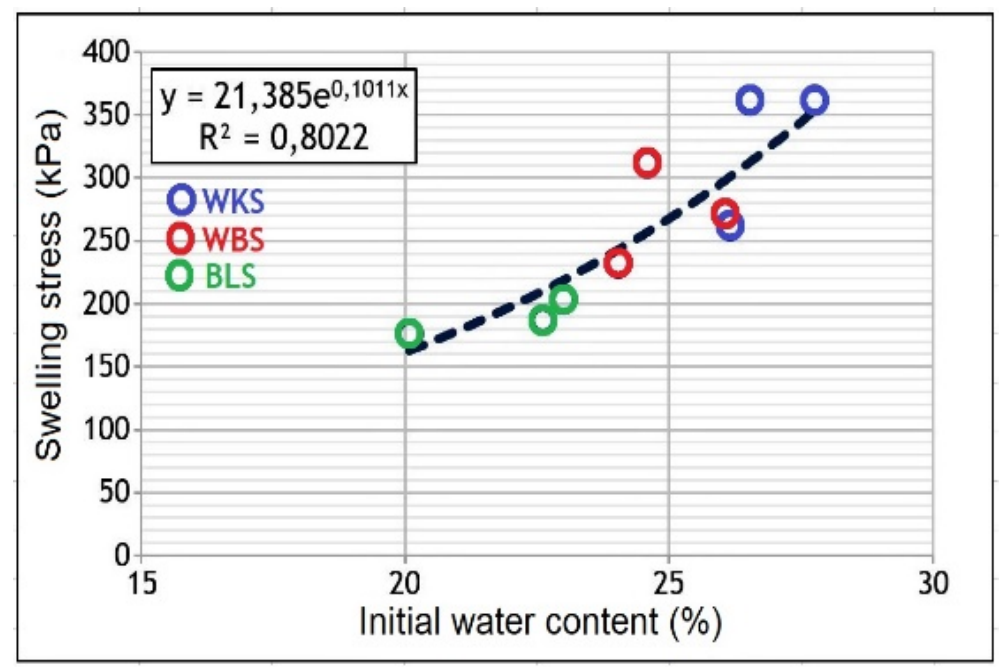

(a) Swelling stress vs initial water content 


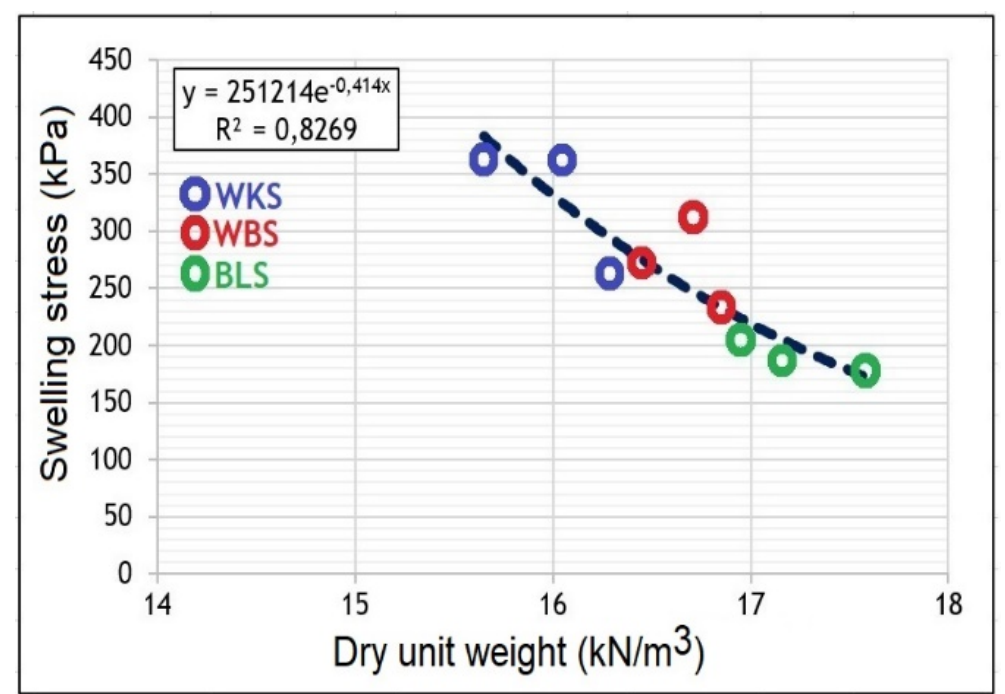

(b) Swelling stress vs dry unit weight

Figure 9. Swelling stress vs initial water content. Dry unit weight @ OWC

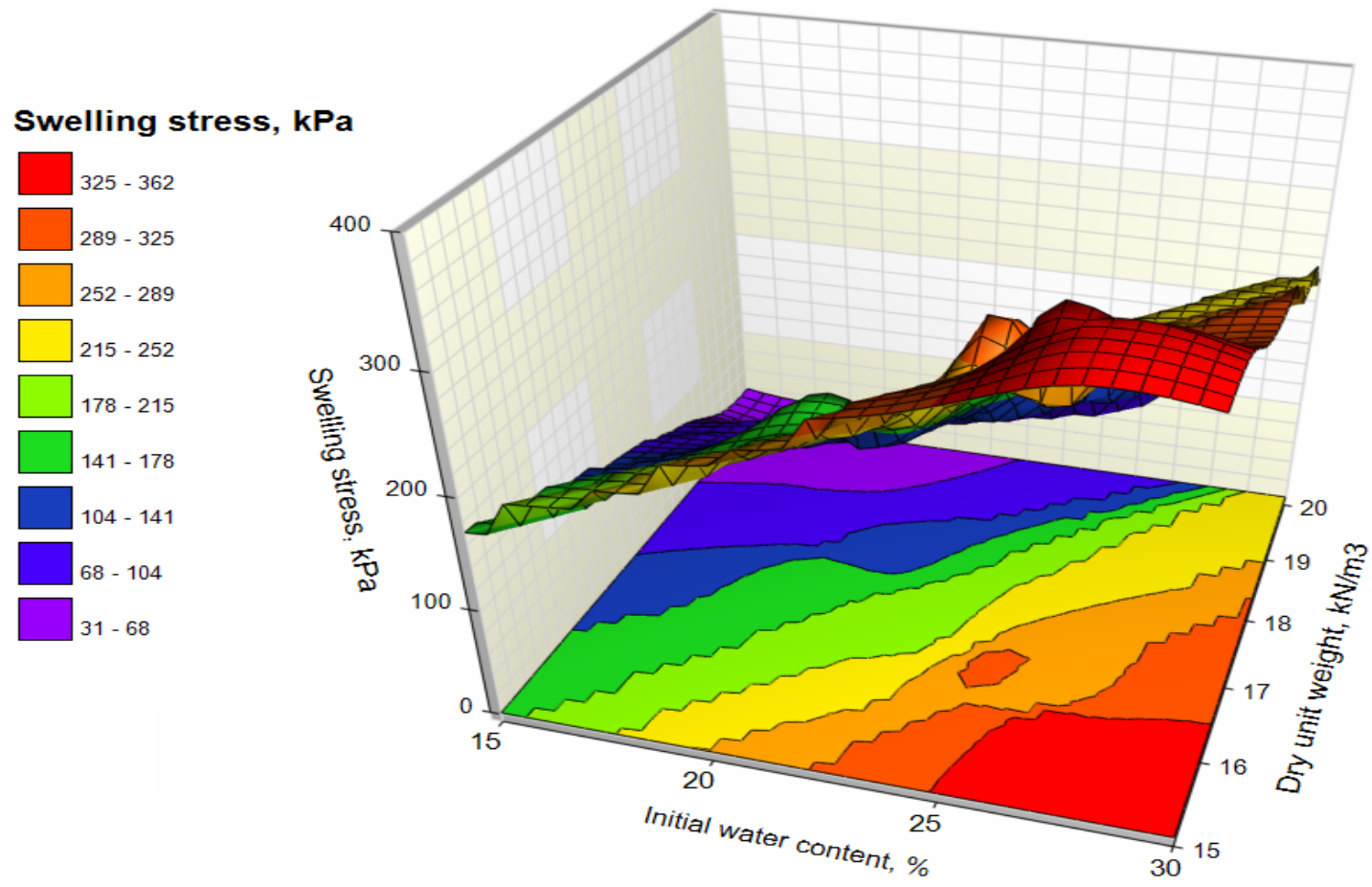

Figure 10. Surface plot of swelling stress vs initial water content. dry unit weight @ OWC

\section{Conclusions}

The values of the matric suction at the optimum water content are within the range of $672 \mathrm{kPa}$ to $2022 \mathrm{kPa}$ and the total suction values within the range of $1036 \mathrm{kPa}$ to $2814 \mathrm{kPa}$. The swelling stress values at the optimum water content are within the range of $177 \mathrm{kPa}$ to $326 \mathrm{kPa}$ which is greater than the bearing limit ( $40 \mathrm{kPa})$ applied for most lightweight footing in the study areas and justify the damages to lightweight structures. Reinforced rafts, modified continuous spread footing, pier beam or pile beam systems are the suitable type of foundations for the areas of the study and must be designed so that the foundation pressure must exceed the swelling stress to prevent uplift force, and the foundation pressure must not exceed the bearing limit of the soil. The swelling stress increases upon the increment of soil suction, and exhibit a strong correlation with $\mathrm{R}^{2}>80 \%$. A strong correlation estimated at $89 \%$ is observed between the swelling stress and the dry unit weight. Very good correlation estimated at $80 \%$ is obtained between the swelling stress and the initial water content. Swelling stress and the initial water content cannot be dissociated. 


\section{REFERENCES}

[1] Agus, S.S., Arifin, Y.F., Tripathy, S. and Schanz, T. (2013), "Swelling pressure-suction relationship of heavily compacted bentonite-sand mixtures", Acta Geotechnica, 8 (2), 155-165. Doi 10.1007/s11440-012-0189-0.

[2] Attom, M.F., Barakat, S. (2000), "Investigation of three methods for evaluating swelling pressure of soils", Environ. Eng. Geosci. 6 293-299. http://worldcat.org/issn/10787275.

[3] ASTM (2009), Standard Test Method for Particle-Size Distribution (Gradation) of Soils Using Sieve Analysis, D 6913; 04. 09, American Society for Testing and Materials, PA, USA. Doi: 10.1520/d6913-04r09.

[4] ASTM (2016), Standard Test Method for Measurement of Soil potential (Suction) using filter paper, D 5298; 04. 08, American Society for Testing and Materials, PA, USA. Doi: 10.1520/d5298-16.

[5] ASTM (2014), Standard Test Method for One-Dimensional Swell or Collapse of Soils, D 4546; 04 .08, American Society for Testing and Materials, PA, USA. Doi: 10.1520/d4546-14e01.

[6] ASTM (2016), Standard Test Method for Particle-size Distribution (Gradation) of Fine-Grained Soils Using the Sedimentation (Hydrometer) Analysis, D 7928; 04. 09, American Society for Testing and Materials, PA, USA. Doi: 10.1520/d7928-16e01.

[7] ASTM (2005), Standard Test Method for Liquid Limit, Plastic Limit, and Plasticity Index of Soils, D 4318; 04. 08, American Society for Testing and Materials, PA, USA. Doi: 10.1520/d4318-17e01.

[8] Basma, A.A., Al-Homoud, A.S. and Malkawi, A.H. (1995), "Laboratory assessment of swelling pressure of expansive soils"., Applied Clay Science, 9 (5), 355-368. https://doi.or g/10.1016/0169-1317(94)00032-L.

[9] BIS, I. (1977), Methods of Test for Soils: IS: 2720-Part 40 Determination of Free Swell Index of Soils. Bureau of Indian Standards, New Delhi, India, 1-5.

[10] Brindley, G.W and Brown, G. (1984), "Crystal Structures of Clay Minerals and Their X-ray Diffraction Identification". London: Mineralogical Society. 495 p.

[11] Cantillo, V., Mercado, V. and Pájara, C. (2017), "Empirical correlations for the swelling pressure of expansive clays in the city of Barranquilla, Colombia", Earth Sciences Research Journal., 21 (1), 45-49 http://dx.doi.org/10.1544 6/esrj.v21n1.60226.

[12] Edlefsen, N. E. and Anderson, A. (1943), Thermodynamics of soil moisture., 15 (2), University of California, USA. Doi:10.3733/hilg.v15n02p031.

[13] Erzin, Y. and Erol, O. (2007), "Swell pressure prediction by suction methods", Engineering Geology, 92 (3-4), 133-145. Doi:10.1016/j.enggeo.2007.04.002.

[14] Fondjo, A.A.(2018), Characterization of swelling stress and soil moisture deficiency relationship for expansive unsaturated soils. Master dissertation, Bloemfontein: Central University of Technology, Free State, South Africa.

[15] Fattom, M. and Barakat, S. (2000), "Investigation of three methods for evaluating swelling pressure of soils", Environmental \& Engineering Geoscience., 6 (3), 293-299. http://worldcat.org/issn/10787275.

[16] Holtz, W.G. (1954), "Engineering properties of expansive clays", Transactions of the American Society of Civil Engineers, 121, 641-677.

[17] Komine, H., Ogata, N. (1994), "Experimental study on swelling characteristics of compacted bentonite". Can. Geotech. J. 31, 478-490. https://doi.org/10.1139/t94-057.

[18] Kandemir, A., Erol, O. and Erzin, Y. (1997), Swell pressure prediction by suction methods, In proceedings of the international conference on soil mechanics and foundation engineering-international society for soil mechanics and foundation engineering, 1, 139-142. AA Balkema.

[19] Lucian, C.(2008), Geotechnical aspect of building on expansive soils in kibaha, Tanzania: Preliminary study. Licenciate Thesis: Stockhlom, Royal Institute of Technology, Sweden.

[20] Nelson, J.D. and Miller, D.J. (1992), Expansive Soils: Problems and Practice in Foundation and Pavement Engineering. New York: Wiley.

[21] Rao, A.S., Phanikumar, B.R. and Sharma, R.S. (2004), "Prediction of swelling characteristics of remoulded and compacted expansive soils using free swell index"., Quarterly Journal of Engineering Geology \& Hydrogeology., 37 (3), 217-226. https://doi.org/10.1144/14 70-9236/03-052.

[22] Rank, K, Metha, J and Bhanderi, J. (2018), "Swelling potential of different expansive soil placed at different dry density and initial water content by constant volume method", International Journal of Innovative Research in Science, Engineering and Technology, 7 (3). DOI: 10.1568 0/IJIRSET.2018.0703016.

[23] Thakur, V. S., \& Singh, D. N. (2005), "Swelling and suction in clay minerals", In Advanced experimental unsaturated soil mechanics Experus, 27-31.

[24] Sridharan, A. and Prakash, K. (2000), "Classification procedures for expansive soils", Proceedings of the Institution of Civil Engineers-Geotechnical Engineering, 143 (4), 235-240. Doi: 10.1007/s41403-016-0001-9.

[25] SABS (2015), Civil Engineering Test Methods, Determination of the Maximum Dry Density and Optimum Moisture Content SANS 3001, Part GR30, South Africa Bureau of Standards. Pretoria.

[26] Sridharan, A., Rao, A.S., Sivapullaiah, P.V. (1986), "Swelling pressure of clays", ASTM Geotech. Test. J. 9 (1), 24-33. https://doi.org/10.1520/GTJ10608J.

[27] Villar, M.V., Lloret, A. (2008), "Influence of dry density and water content on the swelling of a compacted bentonite", Appl. Clay Sci. 39, 38-49. https://doi.org/10.1016/j.clay.20 07.04.007.

[28] Wójcik, E. and Gawriuczenkow, I. (2017), "Determination of swell index and swelling pressure from suction tests- a 
case study of Neogene clays from Warsaw (Poland)", Geotechnical Quaterly., 61 (4), 738-750. Doi: http://dx.doi. org/10.7306/gq.1362.

[29] Zhang, C. and Lu, N. (2018), "Unitary Definition of Matric Suction", Journal of Geotechnical and Geoenvironmental Engineering., 145 (2). https://doi.org/10.1061/(ASCE)GT. 1943-5606.0002004. 